\title{
LA DISYUNTIVA ENTRE CONCIENCIA Y LEY EN EL ORDENAMIENTO CHILENO
}

\author{
Ana María Celis Brunet*
}

\begin{abstract}
Resumen:
Resulta comprensible que en un país en el que subsiste el Servicio Militar Obligatorio, la objeción de conciencia sea ignorada o no prosperen los esfuerzos para incorporarla explícitamente en la normativa nacional. A lo largo de este trabajo se busca poner en evidencia que se deriva de la libertad de conciencia y de religión, por lo que sea o no escrita las personas pueden invocarlas en situaciones de disyuntiva entre el cumplimiento de la ley y obedecer a su propia conciencia. Los aportes provenientes de otros ordenamientos jurídicos iluminan el camino que se emprender para lograr la consolidación del reconocimiento de un derecho fundamental en su plenitud.

Palabras clave: objeción de conciencia, ley, libertad religiosa
\end{abstract}

\begin{abstract}
:
It is understandable that in a country that remains with compulsory military service, conscientious objection is ignored or there is no place to explicitly incorporate it into national law. The article seeks to highlight the fact that it is derived from the freedom of conscience and religion, so whether or not unwritten, everyone may invoke it in situations of disjunction between law enforcement in order to obey their own conscience. Contributions from other legal systems illuminate the path to take to achieve the consolidation of the recognition of a fundamental right in its fullness.
\end{abstract}

Key words: conscious objection, statutory mandate, religious freedom

DOI: $10.7764 / R L D R .1 .3$

\section{LA DISYUNTIVA ENTRE CONCIENCIA Y LEY EN EL ORDENAMIENTO NACIONAL}

Resulta complejo referirse a la objeción de conciencia en un país en el que se alude a las prácticas utilizadas para no constreñir a los jóvenes llamados a prestar el Servicio Militar

\footnotetext{
* Abogado y Doctora en Derecho Canónico, Directora del Centro UC Derecho y Religión (anterior Centro de Libertad Religiosa) y del Departamento de Derecho Canónico de la Facultad de Derecho de la Pontificia Universidad Católica de Chile. En su calidad de profesora ordinaria asociada imparte los cursos de Derecho canónico y Derecho y religión. Fue Secretaria (2005 - 2009) y Presidenta del Consorcio Latinoamericano de Libertad Religiosa (2009 - 2013) y es Vice Presidenta del International Consortium for Law and Religion Studies (ICLARS, 2011 - ). Miembro del Consejo Consultivo del Instituto Nacional de Derechos Humanos (2015 $-)$.
} 
Obligatorio (SMO) como suficiente explicación de su ausencia. En efecto, cada vez que se debe dar cuenta ante organismos internacionales en Chile no reconoce explícitamente la objeción -ni objetores- en la materia más extendida en que suele hacerse, se señala que los cupos se llenan adecuadamente con voluntarios. De ahí que se sostenga que si bien es un servicio obligatorio, en los hechos es voluntario.

Probablemente, se trata de una situación que el Profesor Navarro Floria consideraría un ejemplo digno de la expresión que acuñó sobre el "realismo mágico jurídico" tan extendido en la región. Pero a fin de no banalizar el asunto, es oportuno señalar que al sostener que el SMO en los hechos es voluntario, el Gobierno recurre a un marco explicativo: "La realización obligatoria perdura sólo como criterio subsidiario, para el caso de que el número de voluntarios no sea suficiente para completar las vacantes de reclutamiento, en cuyo caso operará una selección por sorteo" ${ }^{1}$.

El Gobierno de Chile en su último informe al Comité de Derechos Humanos a propósito del art. 18 del Pacto Internacional de Derechos Civiles y Políticos, se refirió a las novedades relativas a la implementación del Reglamento de Asistencia Religiosa en los establecimientos de las Fuerzas Armadas, de Orden y Seguridad Pública ${ }^{2}$ en sus diversas instituciones ${ }^{3}$. Luego, se indicó cómo la Ley № 20.045 que Moderniza el Servicio Militar Obligatorio distinguió entre exenciones -aplicables entre otros a los ministros de culto- y las exclusiones de los descendientes por consanguinidad en línea recta y colateral hasta el segundo grado inclusive de quienes fueron víctimas de violaciones a los derechos humanos o de violencia política ${ }^{4}$.

En el informe se indica que en el período comprendido entre los años 2007 y 2011, los jóvenes que invocaron la exención aludida ascendieron a 691 y 1.132 se acogieron a la

${ }^{1}$ GOBIERNO DE CHILE. Sexto Informe periódico de aplicación del Pacto Internacional de Derechos Civiles y Políticos. De conformidad al artículo 40 del Pacto, Mayo 2012. [en ligne]. p. 26. [Consultado el 29/09/2015]. Disponible en: http://www.minrel.gob.cl/minrel/site/artic/20080902/asocfile/20080902204316/6to_informe_ccpr_civiles_p ol_ticos_mayo_2012_.pdf..

2 DECRETO 155. Ministerio de Defensa que reglamenta la asistencia religiosa en establecimientos de las Fuerzas Armadas y de las de Orden y Seguridad Pública, Subsecretaría de Guerra (Diario Oficial, 26 mayo 2008).

${ }^{3}$ GOBIERNO DE CHILE. Sexto Informe periódico de aplicación del Pacto Internacional de Derechos Civiles y Políticos. De conformidad al artículo 40 del Pacto, Mayo 2012. [en línea]. p. 22-25. [Consultado el 29/09/2015]. Disponible en: http://www.minrel.gob.cl/minrel/site/artic/20080902/asocfile/20080902204316/6to_informe_ccpr_civiles_p ol_ticos_mayo_2012_.pdf.

${ }^{4}$ LEY N² 20.045. Moderniza el Servicio Militar Obligatorio (Diario Oficial, 10 septiembre 2005). Art 42 № 6. 
ISSN 07919-7160

exclusión de los familiares de víctimas de derechos humanos, es decir, un total de 1.823 eventuales conscriptos. Incluso, se dieron las cifras de postulantes y las vacantes de reclutamiento existentes y efectivamente los voluntarios las superaban casi en el doble, afirmándose con ello que era innecesario recurrir a la obligatoriedad del servicio. Y se admite que "La normativa legal vigente no contempla la objeción de conciencia -en sentido propio- para la no realización del servicio militar, el cual constituye un deber constitucional para todo chileno que cumple 18 años. Sin embargo la ley citada en el párrafo anterior ${ }^{5}$ estableció la voluntariedad como criterio prevalente para llenar las vacantes de reclutamiento" ${ }^{6}$.

Si fuese así de simple, implicaría una trivialización de la necesidad de reconocer tanto la objeción como los objetores, haciendo inútil en la práctica llevarla hacia un texto positivo. Es decir, no parece bastar el arreglar lo suficiente la ley para que quienes eventualmente se vieran afectados en su cumplimiento no se pongan en dicho escenario. Y es que no puede considerarse tan inmediato como para que se pretenda que al evitarse la situación ésta desaparezca del todo. Una opción así deja subsistente el que, en definitiva, el no realizar el SMO dependería de una especie de concesión graciosa del Estado y no un derecho fundamental del objetor. Así se desdibuja un derecho fundamental como la libertad de conciencia y de religión relegándosele a un aspecto meramente devocional.

En todo caso, la respuesta de Chile no eliminó la inquietud del Comité de Derechos Humanos que en sus Observaciones señaló que, no obstante la respuesta nacional "sigue preocupado porque la ley vigente no reconozca la objeción de conciencia al servicio militar, como indicó anteriormente. El Estado parte debe agilizar la adopción de una legislación que reconozca la objeción de conciencia al servicio militar" ${ }^{7}$.

Es interesante que en relación a la aplicación del Pacto se considere insuficiente una respuesta basada en la práctica y en algunas excepciones a la ley de reclutamiento para el SMO. De alguna manera ello es coherente con la tutela debida a los derechos

\footnotetext{
${ }^{5}$ Se refiere a la LEY 20.045.

${ }^{6}$ GOBIERNO DE CHILE. Sexto Informe periódico de aplicación del Pacto Internacional de Derechos Civiles y Políticos. De conformidad al artículo 40 del Pacto, Mayo 2012. [en línea]. p. 26. [Consultado el 29/09/2015]. Disponible en: http://www.minrel.gob.cl/minrel/site/artic/20080902/asocfile/20080902204316/6to_informe_ccpr_civiles_p ol_ticos_mayo_2012_.pdf.

${ }^{7} \mathrm{CCPR} / \mathrm{C} / \mathrm{CHL} / \mathrm{CO} / 6$ (2014) p. 7.
} 
fundamentales y proporciona el piso para sostener que la objeción de conciencia existe independientemente de su reconocimiento positivo.

En todo caso, la opción de ofrecer un servicio ciudadano alternativo fue objeto de un proyecto de ley en el pasado gobierno de la presidente Bachelet como parte de su programa, que posteriormente fue archivado sin debatirse.

El 15 de junio de 2006 en virtud de un Mensaje presidencial (№158-354) a la Cámara de Diputados, la Presidenta Bachelet presentó un proyecto de ley para establecer objeción de conciencia al servicio militar obligatorio y crear un servicio ciudadano alternativo tal como se había presentado en su programa de Gobierno: "La iniciativa legal tiene su fundamento en la necesidad de reconocer una exención al servicio militar obligatorio para aquellos jóvenes que, debido a sus convicciones, no puedan darle cumplimiento sin entrar en un grave conflicto de conciencia. Para ello, a través de la creación de una prestación sustitutoria en el Servicio Ciudadano Alternativo, se les permitirá cumplir con dicha carga pública" ${ }^{\prime 8}$.

La propuesta contemplaba una cláusula de conciencia que "tiene causales regladas, las que deben demostrarse en un procedimiento administrativo, cuya resolución final puede impugnarse jurisdiccionalmente (p. 3)" redactada en los siguientes términos: "Artículo $1^{\circ}$. Quedan exentos del cumplimiento del Servicio Militar Obligatorio los varones pertenecientes a la Base de Conscripción que invoquen fundadamente convicciones éticas, religiosas, filosóficas o humanitarias que les impidan, en conciencia, la prestación de dicha carga pública, y que, como consecuencia de ello, hayan sido declarados objetores de conciencia conforme al procedimiento que fije esta ley ${ }^{\prime 9}$. Luego, se establecían limitaciones a su invocación sobreviniente -dando por lo demás un plazo de 30 días para invocarla- o en estado de asamblea (art. 2). Pero lo cierto es que no alcanzó a seguir demasiadas

${ }^{8}$ BACHELET JERIA, Michelle. Mensaje presidencial (N¹58-354) a la Cámara de Diputados de Proyecto de ley sobre objeción de conciencia al servicio militar obligatorio y creación del servicio ciudadano alternativo, 15 Junio de 2006. [en línea]. p.1. [Consultado el 29/09/2015]. Disponible en: HTTPS://WWW.CAMARA.CL/PLEY/PLEY_DETALLE.ASPX?PRMID=4625\&PRMBOLETIN=4235-02. En el Mensaje presidencial se señaló que "El Gobierno ha priorizado dar respuesta a esta necesidad, en primer lugar, porque está establecido como una de las medidas que se comprometió adoptar dentro de los primeros 100 días de su mandato. Ahí se obligó a crear un servicio ciudadano alternativo al servicio militar obligatorio, que permita a los jóvenes realizar actividades de impacto social en beneficio de la comunidad (pp. 1-2)". Ver la tramitación del proyecto hasta su archivo en CORTE SUPREMA. Oficio $N^{\circ} 73$, Informe Proyecto Ley 22-2006 (Boletín $N^{\circ}$ 4235-02). p. 3. https://www.camara.cl/pley/pley_detalle.aspx?prmID=4625\&prmBoletin=4235-02_accesado el 29/09/2015.

9 PROYECTO DE LEY. Introduce la objeción de conciencia como causal de exclusión del cumplimiento del servicio militar, 14 junio 2006 (BOLETÍN 4235-02). 
ISSN 07919-7160

etapas, pues se archivó pendiente el primer trámite constitucional ${ }^{10}$. Previamente, con ocasión de la discusión de la que sería la Ley №20.045 que Moderniza el Servicio Militar Obligatorio, se encontraba una precursora de la cláusula de conciencia propuesta al año siguiente. Los términos entonces fueron redactados así: "las personas cuyas íntimas e imperiosas convicciones religiosas, humanitarias o filosóficas, les impidan, en conciencia, el ejercicio de la actividad militar" ${ }^{11}$. En el oficio que la Corte Suprema alcanzó a enviar, se hizo referencia a asuntos sobre un eventual recurso, resguardos para la notificación de la convocatoria, el silencio ante la invocación de la objeción, etc.

También se archivó el Proyecto que "Incorpora al Código Sanitario la objeción de conciencia para ser invocada por ciertos profesionales para eximirse de vender un determinado producto que pueda perjudicar la vida o la salud humana"12.

En la actualidad, se encuentran en tramitación dos proyectos de ley relativos a la libertad de conciencia en los que se incorpora el reconocimiento de la objeción de conciencia aunque ninguno ha seguido el iter legislativo más allá de la cuenta:

a) Proyecto de Ley que equipara el tratamiento que el Estado y sus agentes, les deben a las distintas iglesias existentes en Chile y, resguarda la objeción de conciencia (Boletín 9563-07) del 10 septiembre 2014. En la Moción se pretende agregar un inc. 4으 al art. 19 № 6 en los siguientes términos: “El Estado de Chile reconoce la plena igualdad de cultos y creencias, por lo tanto, ni funcionario ni autoridad alguna, podrá efectuar discriminaciones arbitrarias que impidan o atenten contra la igualdad de trato que deben recibir las distintas iglesias en cualquier orden de materias, ni se podrá impedir o limitar, bajo ningún pretexto, la libre expresión de sus ideas o símbolos religiosos, ni atentar contra la objeción de conciencia obligándolas a actuar en contra de sus propias creencias o ideas religiosas".

\footnotetext{
${ }^{10}$ Luego de la Cuenta del Proyecto y el Oficio de la Corte Suprema (№ 73), la Comisión de Defensa solicitó su archivo que se realizó el 17 de diciembre de 2008.

${ }^{11}$ Ver en: CORTE SUPREMA. Oficio N³3, Informe Proyecto Ley 22-2006 (Boletín N 4235-02). p. 3.

12 En este caso, la Moción se presentó el Martes 6 de noviembre de 2007, se decretó el archivo del Boletín 5453-11 el 7 de mayo de 2010 luego de dos años sin tramitación: ver en https://www.camara.cl/pley/pley_detalle.aspx?prmID=5840\&prmBoletin=5453-11. En el proyecto se incluía como inciso final del art. 123 del Código Sanitario el siguiente texto: "Sin perjuicio de lo señalado en tos incisos precedentes, los profesionales y técnicos encargados de dirigir una farmacia o almacenes farmacéuticos, no podrán ser obligados por el Servicio de Salud, ni por autoridad alguna, a vender un producto farmacéutico cuando ellos aleguen tener la convicción moral o la duda razonable de que ese producto puede provocar o inducir el aborto o dañar la salud de las personas".
} 
b) Proyecto de Ley que modifica el artículo $19 \mathrm{~N}^{\circ} 6^{\circ}$ de la Constitución Política de la República para asegurar la igualdad de trato a las iglesias, cultos y creencias religiosas y garantizar el derecho de objeción de conciencia (Boletín 9716-07) del 12 noviembre 2014. También se propone agregar un inciso final a la actual garantía fundamental relativa a la libertad de conciencia y de religión. El tenor de la propuesta es: "Todas las iglesias, cultos y creencias gozan del mismo trato igualitario por parte del Estado y sus agentes, no pudiendo limitarse en modo alguno la libre expresión de sus convicciones. Asimismo, toda persona tiene el derecho de objeción de conciencia, ante la imposición de un determinado culto, que violente su libertad de creencias".

Se observa entonces una voluntad de incluir genéricamente la objeción de conciencia sin distinguir materias específicas, lo que es coherente con la tendencia actual. Así ,en Chile eventualmente se comenzaría a instalar en un texto positivo la objeción de conciencia sin que se trate del servicio militar que ha sido la clásica puerta de entrada en este tema.

A ello se suma la rápida discusión en torno al proyecto de ley para introducir el aborto en el país, que ha significado que sea en esta materia donde se concentre hoy el debate de la objeción de conciencia ${ }^{13}$. El texto presentado por Mensaje presidencial el 31 de enero del año en curso, se encuentra en su primer trámite constitucional, habiendo pasado para su estudio desde la Comisión de Salud hacia la de Constitución, Legislación y Justicia (29 septiembre 2015). El Ejecutivo le ha dado urgencia simple.

Sin entrar en este momento al debate sobre el aborto desde la perspectiva de la libertad religiosa, interesa concentrarse específicamente en la objeción de conciencia.

${ }^{13}$ En este momento resulta oportuno recordar que el coqueteo (flirteo) con la objeción de conciencia en materia de derecho a la vida y a la salud, se observó con ocasión de un documento del 2007 que contenía las Normas Nacionales sobre Regulación de la Fertilidad (DECRETO SUPREMO № 48 [2007]) en los que se incorporaba entre los métodos posibles la llamada píldora del día después. Si bien ello fue objeto de diversos requerimientos ante el Tribunal Constitucional, por vía administrativa hoy se vende sin receta en las farmacias. En el texto del Ministerio de Salud de 2007 se referían al derecho a la libertad de pensamiento, de conciencia y de religión, en los siguientes términos: "una sociedad pluralista, en la que conviven personas con diferentes valores y creencias religiosas que requieren respeto y tolerancia, no impone el uso de ningún método anticonceptivo. Por el contrario, se adecua a la diversidad de pensamiento, conciencia y religión de las personas que los utilizan y no pretende influir tampoco en la decisión de no usar un método. Por otra parte, el personal de salud tiene también derecho a considerar que el mecanismo de acción de alguno de los métodos pudiera no ser aceptable para ellas/os. Esta 'objeción de conciencia' los obliga, desde el punto de vista ético, a derivar a quién solicita ese método a otro profesional que no tenga esta objeción, asegurándose que la persona es atendida y puede ejercer sus derechos (DECRETO SUPREMO № 48 [2007] p. 26, sección 1.2)". Desde entonces ha sido una constante ampararse en que se trata de conductas no obligatorias, pero luego aludir a una eventual objeción de conciencia por parte del personal de salud. 
En el Mensaje presidencial se "reconoce el derecho que asiste a toda persona para conducirse en su vida de acuerdo con sus convicciones y principios morales (...). Como se ha dicho, este proyecto encara situaciones difíciles, donde las convicciones profundas de cada persona están en juego. Es por ello que se le reconoce al o la médico(a) cirujano(a) la posibilidad de expresar, por escrito y previamente, su objeción de conciencia. Además, se hace explícito el deber ético del médico afectado por la objeción de conciencia de informar cuando una paciente se encuentra en alguna de las causales. Desde luego, se trata de un derecho propio del médico que interviene, en tanto persona natural. Como contrapartida, el prestador de salud tiene la obligación de derivar a la mujer a un profesional que no esté afectado por la objeción de conciencia. Con todo, la objeción de conciencia no puede ser un obstáculo en aquellos casos excepcionales en que la mujer requiere una interrupción del embarazo de modo inmediato e impostergable y, además, no existe otro médico que pueda realizar la intervención"14.

Como consecuencia de tales declaraciones, la objeción de conciencia se reconoce sólo al médico sin extenderse al personal de salud. Además, se debe declarar de manera escrita y previa, lo que no se considera en el evento que se encuentre una mujer que "requiera atención inmediata e impostergable y no exista otra persona que pueda realizarla". Por último, se impone una doble carga: al prestador de salud para derivar a la paciente a otro médico cirujano y al objetor de informarlo oportunamente" ${ }^{15}$.

Entonces, una nueva redacción del artículo 119 ter sería la siguiente:

El(la) médico(a) cirujano(a) que sea requerido(a) para interrumpir el embarazo en las causales descritas en el artículo 119, podrá abstenerse de realizarlo cuando hubiera manifestado su objeción de consciencia al(la) Director(a) del establecimiento de salud, en forma escrita y previa. El establecimiento tendrá la obligación de reasignar otro médico(a) cirujano(a) a la paciente o de derivarla en forma inmediata para que el procedimiento le sea realizado por quien no haya manifestado dicha objeción. El Ministerio de Salud deberá dictar los protocolos necesarios para le ejecución de la objeción de conciencia. El(la) médico(a) cirujano(a) que ha manifestado objeción en conciencia y es requerido(a) para interrumpir un embarazo, tiene la obligación de informar de inmediato al Director(a) del establecimiento

\footnotetext{
14 BACHELET JERIA, Michelle. Mensaje presidencial (N¹230-362) a la Cámara de Diputados de Proyecto de ley que regula la despenalización de la interrupción voluntaria del embarazo en tres causales, 31 enero 2015. [en línea]. $\quad$ p. III, 3c. [Consultado el 29/09/2015]. Disponible en: HTTPS://WWW.CAMARA.CL/PLEY/PLEY_DETALLE.ASPX?PRMID=4625\&PRMBOLETIN=4235-02.

${ }^{15}$ BACHELET JERIA, Michelle. Mensaje presidencial (N¹230-362) a la Cámara de Diputados de Proyecto de ley que regula la despenalización de la interrupción voluntaria del embarazo en tres causales, 31 enero 2015. [en línea]. [p. IV, 4. [Consultado el 29/09/2015]. Disponible en: HTTPS://WWW.CAMARA.CL/PLEY/PLEY_DETALLE.ASPX?PRMID=4625\&PRMBOLETIN=4235-02.
} 
de salud que la mujer requirente debe ser derivada. En el caso que la mujer requiera atención médica inmediata e impostergable, quien haya manifestado objeción de conciencia no podrá excusarse de realizar la interrupción del embarazo en la medida que no exista otro(a) médico(a) cirujano(a) que pueda realizar la intervención.

En ello se observa a lo menos una virtud y una debilidad. La primera, es el que se tenga la voluntad de incluir por primera vez en el ordenamiento nacional la objeción de conciencia. La flaqueza más evidente es limitarla sólo al médico tratante.

Aunque se invoca al Estado laico, se opta en realidad por una creencia -vestida de neutralidad- relegando las demás convicciones al ámbito privado. Así, el respeto a las creencias es más aparente que real y la objeción de conciencia propuesta, constituye más bien una derivación médica que descansa en la obligación del eventual objetor de cuidar que se realice el aborto y de intervenir el mismo si no lo logra.

Se presenta además como una eventual colisión de derechos: de una parte, el médico y su conciencia y, de otra, lo que se considera el derecho de la mujer a acceder al aborto bajo las causales legales. Pero inmediatamente después se opta por lo que se considera un derecho de la mujer a la salud, lo que plantea numerosos conflictos especialmente si se tiene una postura respecto del inicio de la vida que se aparta notablemente de reconocer concesiones para ponerle término en el vientre materno.

Hasta ahora, a lo más se había estudiado otro tipo de situaciones como eventuales objeciones. Lo interesante de ellas es que no existiendo un texto positivo que amparara la conducta contraria, ocurrió lo que corresponde hacer: recurrir al juez. Fue en sede judicial que en el país se problematizó acerca de los conflictos de conciencia de testigos de Jehová en torno a evitar transfusiones sanguíneas. En un escenario de escasa judicialización de asuntos de libertad de conciencia y de religión que haya una buena cantidad de recursos de protección presentados en el tema considerando que existe un reducido grupo de personas con tales creencias en el país ${ }^{16}$. Si bien en la actualidad han desaparecido prácticamente los recursos de protección en este tema debido a terapias alternativas, también ha dejado de ser estudiado como una objeción real toda vez que se la considera doctrinalmente como una negativa a tratamientos médicos.

En general, se han acogido los recursos de protección en caso que la urgencia subsistiera al momento del fallo aunque existen diversas variables consideradas en las decisiones

\footnotetext{
${ }^{16}$ De acuerdo al Censo 2002, los testigos de Jehová apenas superan el 1\%, que equivale a 119.455 habitantes (INSTITUTO NACIONAL DE ESTADísticas [2002] pp. 25 - 26).
} 
ISSN 07919-7160

judiciales como la participación del recurrido, la desaparición de la urgencia, los riesgos de la transfusión y su incidencia en la sobrevida del paciente ${ }^{17}$.

Es interesante entonces que se haya judicializado casos en torno al derecho a la vida y salud, y que en la actualidad haya entrado el debate acerca de la objeción de conciencia en un escenario de legalización del aborto en el país. No se ingresa entonces desde la objeción al SMO sino que se asume la notable diversificación que el tema vive en la actualidad.

Los profesores Navarro Valls y Martínez Torrón han insistido en que ya no se trata de "objeción de conciencia" sino que es necesario utilizar el plural: objeciones de conciencia. Los grandes expertos en el tema de la objeción plantean que desde hace algún tiempo estalló un "Bing Bang" que ha diversificado la cantidad de materias respecto de las cuales se reconoce la objeción. Consideran que ello se debe a diversas causas que van desde la

${ }^{17}$ Cfr. Alcalde Rodríguez, Enrique. "Derecho a la vida y libertad religiosa: el caso de los Testigos de Jehová », en Revista ACTUALIDAD JURÍDICA N¹9. Tomo II. Enero 2009, p. 621. El autor, recurre a un estudio de casos ocurridos entre los años 1991 y 2003, analizados en Retamales, Avelino, "Lecciones que dejan los pacientes adultos que rechazan transfusiones de sangre a partir de la doctrina de nuestros tribunales" en Ius Publicum №11 (2003), pp. 75-102. En algunas decisiones se ha señalado que se consideran "especialmente justificadas cuando se refieren a menores de edad y a la oposición a tratamientos curativos fundada en razones religiosas de sus padres. Esas razones religiosas, objeto de una decisión de adhesión libre, informada y voluntaria, y que resultan constitucionalmente merecedoras de respeto y protección estatal, no pueden sin embargo determinar la muerte o el riesgo de ella para quien no ha consentido madura y responsablemente en esa adhesión religiosa, como ocurre con los niños" (en Corte de Apelaciones de Valdivia, "Gomez Noa (menor)", causa rol 103/2009, del 14 de mayo de 2009, considerando undécimo). En otras ocasiones que han afectado a menores de edad, se ha recurrido incluso a una segunda transfusión ordenada judicialmente, para luego continuar con el sistema médico alternativo propuesto por los padres con la colaboración de un profesional experto. Cfr. en Cfr. Corte de Apelaciones de San Miguel, "Director del Servicio de Salud Metropolitano Sur con Mirla Isasmendi Cartagena - Javier Fuentealba Reinoso", causa rol 123-2004, 22 de mayo de 2004 , considerando 8․ La Corte Suprema, confirmó la sentencia de la Corte de San Miguel que rechazó el recurso: al decretarse la transfusión como medida preventiva, se acogió lo solicitado aunque debía resolverse en sentencia definitiva (considerandos 5으 a 7으). Alguna vez se ha acogido la solicitud de un marido, si bien su mujer había manifestado notarialmente su oposición a una transfusión sanguínea en un Poder de Atención Médica $^{17}$. La conclusión del caso sin embargo, se precipitó ante la muerte de la paciente sin habérsele realizado la transfusión, ni se hubiera pronunciado la Corte Suprema respecto de la apelación interpuesta por miembros de la confesión religiosa. La decisión se había planteado en los términos actualmente habituales, esto es, "sólo en cuanto se autoriza a los médicos de la Clínica Indisa para que procedan a efectuar los métodos clínicos de transfusión de sangre que sean médicamente necesarios para la conservación y recuperación de la salud de la paciente". Cfr. Corte de Apelaciones de Santiago, "Enrique Cantero Alcaide contra Clínica Indisa", causa rol 4330-2008, 5 de julio de 2008. 
crisis del positivismo legalista a motivaciones sinceras y a una "progresiva metamorfosis del propio instituto" ${ }^{18}$.

El Profesor Palomino, presenta con claridad los contenidos y alcances de objeciones de conciencia a deberes cívicos (militar, fiscal, jurado y elecciones), relativas a la vida humana (aborto y tratamientos médicos) y las relaciones laborales (calendario laboral y vestimenta), agregando otras formas de objeciones de conciencia en cuanto a normas administrativas y las situaciones de empleados públicos y jueces ${ }^{19}$. El destacado académico sostiene parte del supuesto que no todo incumplimiento es igual y que "la desobediencia al Derecho por motivos de conciencia es un marcador identitario que identifica la civilización occidental" 20 .

Una muestra de resolver "a la chilena" los conflictos sin contar de manera explícita con el reconocimiento de la objeción de conciencia, sucedió en el caso de un funcionario de policía adventista cuando le correspondió un turno en día sábado. Es particularmente interesante que no haya ninguna referencia a una objeción de conciencia sino que se haya intentado resolver a través de una conversación con la autoridad superior para que, llegado el momento, su ausencia se haya interpretado como una desobediencia a una orden disposiciones administrativas sobre su turno- y no se considerara la libertad religiosa del funcionario. En efecto, la Corte de Apelaciones de Valparaíso rechazó el recurso de protección estimando que:

a juicio de esta Corte no se ha vulnerado el derecho que le asiste al recurrente de practicar y manifestar el culto religioso que profesa, y por ende no se ha infringido la Garantía Constitucional establecida en el $N^{\circ} 6$ del artículo 19 de nuestra Constitución Política de la República, ni La Ley 19.638, cuestión que la propia Policía de Investigaciones en su Reglamento de Asistencia Religiosa reconoce al establecer en su artículo 4 que 'Todos los miembros de la Policía de Investigaciones de Chile y su grupo familiar, tienen derecho a profesar y practicar el credo o creencia religiosa que deseen, o ninguna libremente'. En efecto, la situación que se ha originado respecto al recurrente quien ha sido sancionado por su superior jerárquico, no dice relación con un impedimento para desarrollar y practicar su religión, sino con haber actuado al margen de los procedimientos establecidos en la Institución a la cual pertenece desde hace varios años, para justamente haber logrado eliminar las trabas, que estimó le afectaban para asistir al culto el día sábado, cuestión que le competía a él plantear, máxime cuando no cuestionó cuando le fue notificada, la resolución que le impuso la obligación de trabajar el día sábado, habiendo el recurrente de acuerdo a los antecedentes

\footnotetext{
18 NAVARRO VALLS, R. Martínez Torrón, J. en : Conflictos entre conciencia y ley: las objeciones de conciencia. Vol. 2. Madrid : Iustel, 2012, p. 30.

19 PALOMINO, Rafael. Manual Breve de Derecho Eclesiástico del Estado. Universidad Complutense, p. $120-136$.

${ }^{20}$ PALOMINO, Rafael. Manual Breve de Derecho Eclesiástico del Estado. Universidad Complutense, p. 113. A continuación de ello pasa por diversos hechos y personajes históricos o de ficción que han optado por seguir su conciencia en un determinado momento.
} 
ISSN 07919-7160

allegados a este recurso, actuado en estas condiciones, sin respetar una orden dada por sus superiores, en una institución que tiene un régimen jerárquico y disciplinario estricto, donde no puede quedar entregado a su mera voluntad el no acatar órdenes, sobre todo cuando el fin de ella es velar por la tranquilidad y el orden público. Lamentablemente, la sanción recibida como una falta seria que afectará su calificación laboral ${ }^{21}$.

En el fondo, en este caso no se siguió el procedimiento establecido en la propia institución para ejercer la libertad religiosa. Obviamente, se requieren ciertas formalidades para invocar en cada situación la objeción de conciencia, en especial para verificar que la motivación de la persona sea lo suficientemente seria como para desestimar un capricho o simple desidia respecto del cumplimiento de las obligaciones personales. No obstante ello, se comprende la situación en el marco de la informalidad nacional que supone que basta con avisar o "negociar" para que todo quede en orden. En el caso presentado, el funcionario arriesgó con ello su calificación exponiéndolo a una eventual pérdida de trabajo.

En este contexto nacional, no cabe duda entonces que "el derecho a la libertad religiosa posee una composición que plantea desafíos para un Estado no confesional y democrático" ${ }^{22}$. La objeción de conciencia es precisamente un ámbito que parece haberse instalado y que habrá de resolverse de manera que se garantice que en Chile se puede vivir de acuerdo a las propias convicciones o creencias. No es por tanto suficiente argumentar que se está ante situaciones no obligatorias -en el estilo de "si quiere aborte, pero sepa que nadie le constriñe a hacerlo" - si al final, ello implica que las propias creencias pasan a ser ilícitas. Así, se abre la necesidad de invocar la objeción de conciencia en las más variadas materias.

\section{UNA MIRADA A LA VECINDAD Y MÁS ALLÁ}

La idea de que el pasto del vecino es siempre más verde, obliga a extender la mirada a los países de la región y al aporte en la materia desde el sistema americano de derechos humanos y de la ONU.

Por de pronto, en el Informe acerca de Paraguay, el Relator Especial sobre la libertad de religión o de creencias "celebra que el art. 37 de la Constitución reconozca expresamente el derecho a la objeción de conciencia por razones éticas o religiosas. Además, el número

\footnotetext{
${ }^{21}$ Silva Montero, EduARdo contra Policía InVESTigaciones de CHILE (2014) considerando décimo.

22 INSTITUTO NACIONAL DE DERECHOS HUMANOS. Situación de los Derechos Humanos en Chile 2014, [en línea]. p. 167. [Consultado el 15/09/2015]. Disponible en: http://www.indh.cl/informe-anual-situacion-delos-derechos-humanos-en-chile-2014.
} 
relativamente elevado de objetores de conciencia en el Paraguay demuestra que actualmente la garantía constitucional objeción de conciencia al servicio militar obligatorio se respeta en la práctica. Sin embargo, el Comité de Derechos Humanos lamentó, en sus observaciones finales de octubre de 2005 sobre el Paraguay que las zonas rurales no parecían contar con acceso a la información sobre la objeción de conciencia y recomendó la difusión adecuada de información sobre su ejercicio entre toda la población” ${ }^{23}$. Es decir, acá derechamente el relator se refiere al "derecho" a la objeción de conciencia. Luego, Bielefeldt se concentra en el procedimiento establecido para el reconocimiento de los objetores de conciencia y enfatiza la necesidad de imparcialidad de los procesos y presenta preguntas en torno a las asociaciones de objetores (№55). Finalmente, se refiere a servicios sustitutivos comparables (№56).

En el caso de Chile, el Comité de Derechos Humanos señaló que "Pese a la información suministrada por el Estado parte de que la normativa vigente establece la voluntariedad como criterio prevalente para llenar las vacantes de reclutamiento y que la realización obligatoria perdura solo como criterio subsidiario, el Comité sigue preocupado por que la ley vigente no reconozca la objeción de conciencia al servicio militar como indicó anteriormente (CCPR/C/CHL/CO/5, párr. 13) (art. 18). El Estado parte debe agilizar la adopción de una legislación que reconozca la objeción de conciencia al servicio militar" 24 .

Y es que tal como ha sido desde la Observación General № $22^{25}$ se ha extendido la cantidad de personas que "han reivindicado el derecho a negarse a cumplir el servicio militar (objeción de conciencia) sobre la base de que ese derecho se deriva de sus libertades en virtud del artículo 18 (№11)". De manera que sigue siendo de relevancia un tema que no se ha afrontado debidamente en el país contentándose con soluciones "a la chilena".

En el texto se señala a continuación una formulación que ha transformado en clásica si bien reviste de cierta ambigüedad: "En el Pacto no se menciona explícitamente el derecho a la objeción de conciencia pero el Comité cree que ese derecho puede derivarse del artículo 18, en la medida en que la obligación de utilizar la fuerza mortífera puede entrar en grave conflicto con la libertad de conciencia y el derecho a manifestar y expresar creencias

\footnotetext{
${ }^{23}$ BIELEFELDT, Heiner. Informe del Relator Especial sobre libertad de religión o de creencias. Misión al Paraguay 26 enero 2012 (A/HRC/19/60/Add.1). № 54.

${ }^{24}$ Comité de Derechos Humanos. Observaciones finales sobre el sexto informe periódico de Chile 13 agosto 2014 (CCPR/C/CHL/CO/6). № 24.

${ }^{25}$ OBSERVACIÓN GENERAL N ${ }^{\circ} 22$. Comentarios generales adoptados por el Comité de los Derechos Humanos, Artículo 18 - Libertad de pensamiento, de conciencia y de religión (HRI/GEN/1/Rev.7 at 179 [1993]). [№ 11.
} 
ISSN 07919-7160

religiosas u otras creencias" 26 . Algunos estiman que se desprende que la objeción de conciencia se derivaría de la libertad de conciencia y religión tanto en cuanto estuviera explícitamente mencionada en la legislación interna.

No obstante ello, es posible contextualizar la preocupación de entonces por el tema del servicio militar que hoy se ha visto ampliamente superado con el incumplimiento de otros deberes jurídicos invocando la supremacía de la propia conciencia. El punto fundamental entonces, aparece como la incapacidad del Estado para asir o regular la conciencia y en ello no se encuentra una debilidad sino precisamente se evidencia la grandeza de supeditar cualquier norma aquello que emana de la dignidad de cada persona que hace indispensable reconocer derechos fundamentales.

En los instrumentos internacionales, la libertad de conciencia se relaciona con el servicio militar que explícitamente se considera que no es un trabajo forzoso u obligatorio. Para ilustrarlo, es posible detenerse en que tanto en el Pacto de Derechos Civiles y Políticos como en la Convención Americana de Derechos Humanos además de la libertad de conciencia se prevé la eventual prestación del servicio militar.

En el Pacto, el art. 18 se señala que: "1. Toda persona tiene derecho a la libertad de pensamiento, de conciencia y de religión; este derecho incluye la libertad de tener o de adoptar la religión o las creencias de su elección, así como la libertad de manifestar su religión o sus creencias, individual o colectivamente, tanto en público como en privado, mediante el culto, la celebración de los ritos, las prácticas y la enseñanza. 2. Nadie será objeto de medidas coercitivas que puedan menoscabar su libertad de tener o de adoptar la religión o las creencias de su elección. 3. La libertad de manifestar la propia religión o las propias creencias estará sujeta únicamente a las limitaciones prescritas por la ley que sean necesarias para proteger la seguridad, el orden, la salud o la moral públicos, o los derechos y libertades fundamentales de los demás. 4. Los Estados Partes en el presente Pacto se comprometen a respetar la libertad de los padres y, en su caso, de los tutores legales, para garantizar que los hijos reciban la educación religiosa y moral que esté de acuerdo con sus propias convicciones".

Pero antes, en el mismo documento, se establece que "Nadie será constreñido a ejecutar un trabajo forzoso u obligatorio (Artículo 8, 3 a)" y en la letra c) se indica que "'No se considerarán como "trabajo forzoso u obligatorio", a los efectos de este párrafo: ii) El

\footnotetext{
${ }^{26}$ OBSERVACIÓN GENERAL N 22. Comentarios generales adoptados por el Comité de los Derechos Humanos, Artículo 18 - Libertad de pensamiento, de conciencia y de religión (HRI/GEN/1/Rev.7 at 179 [1993]). № 11.
} 
servicio de carácter militar y, en los países donde se admite la exención por razones de conciencia, el servicio nacional que deben prestar conforme a la ley quienes se opongan al servicio militar por razones de conciencia".

En la Convención Americana de Derechos Humanos, la libertad de conciencia se reconoce en términos similares: "Art. 12: 1. Toda persona tiene derecho a la libertad de conciencia y de religión. Este derecho implica la libertad de conservar su religión o sus creencias, o de cambiar de religión o de creencias, así como la libertad de profesar y divulgar su religión o sus creencias, individual o colectivamente, tanto en público como en privado. 2. Nadie puede ser objeto de medidas restrictivas que puedan menoscabar la libertad de conservar su religión o sus creencias o de cambiar de religión o de creencias. 3. La libertad de manifestar la propia religión y las propias creencias está sujeta únicamente a las limitaciones prescritas por la ley y que sean necesarias para proteger la seguridad, el orden, la salud o la moral públicos o los derechos o libertades de los demás. 4. Los padres, y en su caso los tutores, tienen derecho a que sus hijos o pupilos reciban la educación religiosa y moral que esté de acuerdo con sus propias convicciones".

Y en lo que respecta al servicio militar, el art. 6 prohíbe la esclavitud y la servidumbre en los siguientes términos: "3. No constituyen trabajo forzoso u obligatorio, para los efectos de este artículo: b. el servicio militar y, en los países donde se admite exención por razones de conciencia, el servicio nacional que la ley establezca en lugar de aquél".

Al respecto, la Comisión Americana de Derechos Humanos se pronunció en un caso presentado por jóvenes chilenos quienes no obstante haberse anticipado y presentado su negativa al SMO en caso de ser convocados, fueron igualmente llamados ${ }^{27}$. Si bien la Comisión se declaró competente per consideró inadmisible el caso (№ 107), es interesante por la manera en que lo aborda. Los comisionados se preguntaron derechamente: “¿Admite el artículo 12 de la Convención Americana una lectura en el sentido de que una persona puede invocar la condición de objetor de conciencia como fundamento para una exención del servicio militar obligatorio? Si y no (№ 85)". Luego señalaron que se "reconoce expresamente el derecho a la condición de objetor de conciencia en los países en que esta condición está reconocida (№ 86)" y que en Chile eso no ocurre ni se consideran obligados en virtud del art. 6.3.b que admite limitaciones en virtud del servicio militar (№ 97).

Pero más que la mera transcripción de las normas y la inadmisibilidad de las pretensiones de los jóvenes chilenos, resulta interesante observar aquello que se ha ido consolidando en

${ }^{27}$ COMISIÓN INTERAMERICANA DERECHOS HUMANOS. Caso Cristián Daniel Sahli Vera y otros con Chile 10 marzo 2005. 
ISSN 07919-7160

toro al servicio militar resultando que lejos de banalizarse el tema, se ha tenido la capacidad de detenerse en las diversas problemáticas que presenta. Por de pronto, un autor considera que el caso referido "es uno de los realmente paradigmáticos del sistema interamericano de derechos humanos en torno al artículo 12 de la Convención y no sería extraño que en el futuro pronto veamos una sentencia de la misma Corte Interamericana pronunciándose sobre el tema, ya que las últimas décadas han visto un renacimiento de la objeción de conciencia por múltiples motivos religiosos” ${ }^{28}$.

Entre otras, que "El derecho a la objeción de conciencia al servicio militar se considera como forma legítima de ejercer el derecho a la libertad de pensamiento, de conciencia y de religión" ${ }^{29}$.

Para ello se ha "recopilación y análisis de las prácticas óptimas en relación con el reconocimiento de este derecho (№ 38)" a la objeción de conciencia cuyo análisis puede contribuir a iluminar otras materias en las cuales la persona rechaza cumplir la ley del Estado por cumplir una norma superior. El elenco establecido por el Consejo Económico y Social contempla las siguientes buenas prácticas:

a) Aceptación de la solicitud de reconocimiento de la condición de objetor de conciencia sin proceder a una investigación;

b) El procedimiento de adopción de decisiones debe ser independiente, imparcial y no discriminatorio;

c) La objeción de conciencia al servicio militar deriva de principios y razones de conciencia, en particular convicciones profundas, por motivos de orden religioso, moral, ético, humanitario u otros de la misma naturaleza;

d) El derecho debe poder ser ejercido antes del servicio militar y durante el mismo;

e) Las diversas formas de servicio sustitutorio deben ser compatibles con los motivos de la objeción de conciencia, de carácter civil o no combatiente, de utilidad pública y no deben tener carácter punitivo;

f) Se deben adoptar medidas para garantizar que los objetores de conciencia no estén sujetos a sanciones penales reiteradas por incumplimiento del servicio militar;

g) No debe haber discriminación contra los objetores de conciencia en lo que respecta a las condiciones de servicio o a sus derechos económicos, sociales, culturales, civiles o políticos;

\footnotetext{
${ }^{28}$ HUACO PALOMINO, MARCOS. Art. 12. Libertad de conciencia y de religión en Christian Steiner - Patricia Uribe (eds.), Convención Americana sobre Derechos Humanos. p. 311-312.

29 COMISIÓN DE DERECHOS HUMANOS. LOS derechos civiles y políticos, en particular las cuestiones relacionadas con la objeción de conciencia al servicio militar. Informe de la Oficina del Alto Comisionado para los Derechos Humanos 16 febrero 2004 (E/CN.4/2004/55). Resumen.
} 
h) Debe concederse asilo a los objetores de conciencia obligados a abandonar su país de origen por temor a ser perseguidos a causa de su negativa a cumplir el servicio militar;

i) Debe facilitarse a todas las personas interesadas información sobre el derecho a la objeción de conciencia al servicio militar y los medios para obtener el reconocimiento de la condición de objetor de conciencia.

La consideración creciente hacia otros ámbitos en los cuales sea posible invocar la objeción de conciencia y en ese sentido la Asamblea Parlamentaria del Consejo de Europa ha dado pasos importantes.

La Resolución 1763 (2010) se refirió al derecho a la objeción de conciencia en ámbito de los cuidados médicos señalando que "1. No person, hospital or institution shall be coerced, held liable or discriminated against in any manner because of a refusal to perform, accommodate, assist or submit to an abortion, the performance of a human miscarriage, or euthanasia or any act which could cause the death of a human foetus or embryo, for any reason". Y aunque ello va acompañado de ciertas ambigüedades que hacen complejo maginar cómo se pretende no obstante asegurar el cuidado del paciente, se trata de un reconocimiento sustantivo a la objeción más allá del servicio militar.

Asimismo, la Resolución 1928 (2013) "Safeguarding human rights in relation to religion and belief, and protecting religious communities from violence" en virtud de la cual se insta a los estados miembros a asegurar el derecho a la objeción de conciencia materias morales sensibles como el servicio militar, salud y educación (№ 9. 11)

Tal como lo ha planteado el Profesor Navarro Valls, la proliferación de objeciones de conciencia no depende exclusivamente del conflicto individual con una norma determinada, sino que se constituye en la salida jurídica a lo que denomina la "incontinencia normativa del poder" ${ }^{31}$ que al extremar las posturas no deja más opciones que invocar la objeción de conciencia. Las consecuencias de ello se observan en las disimiles decisiones judiciales "Precisamente porque frente a él caben dos posiciones: entenderlo como una especia de 'delirio religioso', una recusable excepción a la norma

\footnotetext{
30 RESOLUCIÓN 1928. Asamblea Parlamentaria del Consejo de Europa, 24 de abril de 2013. [en línea]. [Consultado el 28/09/2015]. Disponible en: http://assembly.coe.int/nw/xml/XRef/Xref-XML2HTMLen.asp?fileid=19695\&lang=en: № 9.11 "ensure the right to well-defined conscientious objection in relation to morally sensitive matters, such as military service or other services related to health care and education, in line also with various recommendations already adopted by the Assembly, provided that the rights of others to be free from discrimination are respected and that the access to lawful services is guaranteed".

31 NAVARRO VALLS, Rafael. Un 'Bing Bang' jurídico: conciencia contra ley [en línea]. Disponible en: http://blogs.elconfidencial.com/espana/tribuna/2015-01-07/un-big-bang-juridico-conciencia-contraley_617063/.
} 
ISSN 07919-7160

legal que conviene restringir o, al contrario, entenderlo como una derivación evidente del derecho fundamental a la objeción de conciencia, un verdadero derecho humano".

En estas palabras parece ubicarse la situación chilena, pues al final la falta de reconocimiento e incluso de problematizaciones en torno a la disyuntiva que presenta el cumplimiento de la ley, lo que parece es que al final, la libertad de conciencia y de religión aparece como un asunto devocional, de segundo orden frente a los que serían derechos fundamentales reales. Más allá de desconocerse de esta manera toda la historia y tradición jurídicas, evidencia que no basta con multiplicar las objeciones de conciencia sino que un sano realismo exige adentrarse meas aún en la comprensión y consolidación de la misma libertad de conciencia y de religión.

Y tal como sostiene el Profesor Palomino, "el punto de referencia último no es el ordenamiento jurídico religioso -lo cual presupondría una normativa uniforme y reconocible, cosa que no suele suceder necesariamente- sino la libertad de conciencia individual" 32 . Ello no obsta para que la objeción de conciencia motivada en las creencias religiosas tenga una relevancia que el académico sintetiza en la diversificación de las mismas en cuanto a los variados ámbitos en los que se presenta, que los fundamentos de la misma en el ordenamiento interno sea en el derecho fundamental a la libertad religiosa y como expresión de la sinceridad del objetor ya que no depende de una postura subjetiva sino fácilmente comprobable en las enseñanzas de su religión ${ }^{33}$.

Lo que ocurre es que "La libertad de religión o de creencias institucionaliza el debido respeto hacia todos los seres humanos como poseedores potenciales de profundas convicciones que configuran la identidad y prácticas basadas en convicciones ${ }^{34 \prime \prime}$

Luego, lo positivo de incluir un texto sobre la objeción de conciencia en cualquier materia independientemente de una redacción deficitaria o incompleta- es su contribución a la seguridad jurídica, aunque en el evento que no se estableciera una norma explícita, debe igualmente sostenerse que siempre se puede invocar la objeción de conciencia. Y es que si bien a nivel positivo se trata de un tema reciente, tanto en la vida real como ficticia es posible encontrar numerosos ejemplos de quienes han demostrado su heroísmo al seguir los dictados de la propia conciencia. Lejos de tratarse de un capricho, lo que se realiza es un

\footnotetext{
32 PALOMINO, Rafael. Manual Breve de Derecho Eclesiástico del Estado: Universidad Complutense, p. 121.

33 PALOMINO, Rafael. Manual Breve de Derecho Eclesiástico del Estado: Universidad Complutense, p. 121.

${ }^{34}$ BIELEFELDT, Heiner. Informe del Relator Especial sobre libertad de religión o de creencias, 26 enero 2013 (A/HRC/25/58). № 32 .
} 
acto de obediencia a aquello que se considera una ley superior, optando por dar primacía a la conciencia.

Entonces, sería limitar la ya compleja situación de los ordenamientos jurídicos al servicio de una proliferación de leyes el considerar que sólo lo que se encuentra escrito como posibilidad de objeción es lo que en realidad existe. Si el derecho llega luego de sucedidos los hechos sociales que promueve la dictación de la norma, en el caso de la objeción de conciencia, ello corre el riesgo de nunca alcanzar los dilemas que se presentan por el dinamismo social imperante.

En ese sentido, si se quiere -y para evitar la rigidez de tenerlo todo por escrito y establecer que fuera de ese marco nada existe- una cláusula general podría ser más eficaz que diversas normas que establezcan condiciones similares. Igualmente, el caso concreto será llevado al juez, a quien corresponderá ponderar adecuadamente.

Efectivamente, al Estado no le corresponde determinar cómo y de qué forma se afecta a los ciudadanos en sus convicciones más profundas. Por lo mismo, el reconocimiento de la objeción de conciencia se encuentra ya en el derecho toda vez que se reconoce la libertad de conciencia constituyendo la negativa a actuar contra ella, simplemente otra faz de la misma. En ocasiones ello se identifica doctrinalmente con la inmunidad de coacción pues en definitiva, así como se reconoce a toda persona el derecho a creer o no creer y cambiar sus creencias y convicciones, igualmente nadie puede ser obligado a actuar contra dichas creencias o convicciones.

Tratar a la objeción de conciencia como una suerte de capricho que bien puede ceder ante las normas del Estado, en el fondo es menospreciar la primacía de la conciencia ante el Estado-laico o no-debe inclinarse.

\section{BIBLIOGRAFÍA}

Alcalde Rodríguez, Enrique. «Derecho a la vida y libertad religiosa: el caso de los Testigos de Jehová », en Revista ACTUALIDAD JURÍDICA N¹9. Tomo II. Enero 2009

BACHELET JERIA, Michelle. Mensaje presidencial (N¹58-354) a la Cámara de Diputados de Proyecto de ley sobre objeción de conciencia al servicio militar obligatorio y creación del servicio ciudadano alternativo, 15 Junio de 2006. [En línea]. [Consultado el 29/09/2015]. Disponible

en :

https://www.camara.cl/pley/pley_detalle.aspx?prmid=4625\&prmboletin=4235-02

BACHELET JERIA, Michelle. Mensaje presidencial ( $\left.N^{\circ} 1230-362\right)$ a la Cámara de Diputados de Proyecto de ley que regula la despenalización de la interrupción voluntaria del embarazo 
ISSN 07919-7160

en tres causales, 31 enero 2015. [En línea]. [Consultado el 29/09/2015]. Disponible en: https://www.camara.cl/pley/pley_detalle.aspx?prmid=4625\&prmboletin=4235-02

BIELEFELDT, Heiner. Informe del Relator Especial sobre libertad de religión o de creencias, 26 enero 2013 (A/HRC/25/58).

BIELEFELDT, Heiner. Informe del Relator Especial sobre libertad de religión o de creencias. Misión al Paraguay 26 enero 2012 (A/HRC/19/60/Add.1).

COMISIÓN DE DERECHOS HUMANOS. Los derechos civiles y políticos, en particular las cuestiones relacionadas con la objeción de conciencia al servicio militar. Informe de la Oficina del Alto Comisionado para los Derechos Humanos 16 febrero 2004 (E/CN.4/2004/55).

COMISIÓN INTERAMERICANA DERECHOS HUMANOS. Caso Cristián Daniel Sahli Vera y otros con Chile 10 marzo 2005.

Comité de Derechos Humanos. Observaciones finales sobre el sexto informe periódico de Chile 13 agosto 2014 (CCPR/C/CHL/CO/6).

CORTE SUPREMA. Oficio N73, Informe Proyecto Ley 22-2006 (Boletín N4235-02).

DECRETO 155. Ministerio de Defensa que reglamenta la asistencia religiosa en establecimientos de las Fuerzas Armadas y de las de Orden y Seguridad Pública, Subsecretaría de Guerra (Diario Oficial, 26 mayo 2008).

GOBIERNO DE CHILE. Sexto Informe periódico de aplicación del Pacto Internacional de Derechos Civiles y Políticos. De conformidad al artículo 40 del Pacto, Mayo 2012. [En línea]. [Consulté le 29/09/2015]. Disponible en : http://www.minrel.gob.cl/minrel/site/artic/20080902/asocfile/20080902204316/6to_infor me_ccpr_civiles_pol_ticos_mayo_2012_.pdf

HUACO PALOMINO, MARCOS. Art. 12. Libertad de conciencia y de religión en Christian Steiner - Patricia Uribe (eds.), Convención Americana sobre Derechos Humanos.

INSTITUTO NACIONAL DE DERECHOS HUMANOS. Situación de los Derechos Humanos en Chile 2014, [en línea]. [Consultado el 15/09/2015]. Disponible en: http://www.indh.cl/informe-anual-situacion-de-los-derechos-humanos-en-chile-2014

LEY N ${ }^{0}$ 20.045. Moderniza el Servicio Militar Obligatorio (Diario Oficial, 10 septiembre 2005).

NAVARRO VALLS, R. Martínez Torrón, J. En: Conflictos entre conciencia y ley: las objeciones de conciencia. Vol. 2. Madrid : Iustel, 2012, p. 188 y s.s. 
NAVARRO VALLS, Rafael. Un 'Bing Bang' jurídico: conciencia contra ley [en línea]. Disponible en : $\quad$ http://blogs.elconfidencial.com/espana/tribuna/2015-01-07/un-big-bang-juridicoconciencia-contra-ley_617063/

OBSERVACIÓN GENERAL N²2. Comentarios generales adoptados por el Comité de los Derechos Humanos, Artículo 18 - Libertad de pensamiento, de conciencia y de religión (HRI/GEN/1/Rev.7 at 179 [1993]).

PALOMINO, Rafael. Manual Breve de Derecho Eclesiástico del Estado: Universidad Complutense.

PROYECTO DE LEY. Introduce la objeción de conciencia como causal de exclusión del cumplimiento del servicio militar, 14 junio 2006 (BOLETín 4235-02).

RESOLUCIÓN 1928. Asamblea Parlamentaria del Consejo de Europa, 24 de abril de 2013. [En línea]. [Consultado el 28/09/2015]. Disponible en: http://assembly.coe.int/nw/xml/XRef/Xref-XML2HTML-en.asp?fileid=19695\&lang=en 